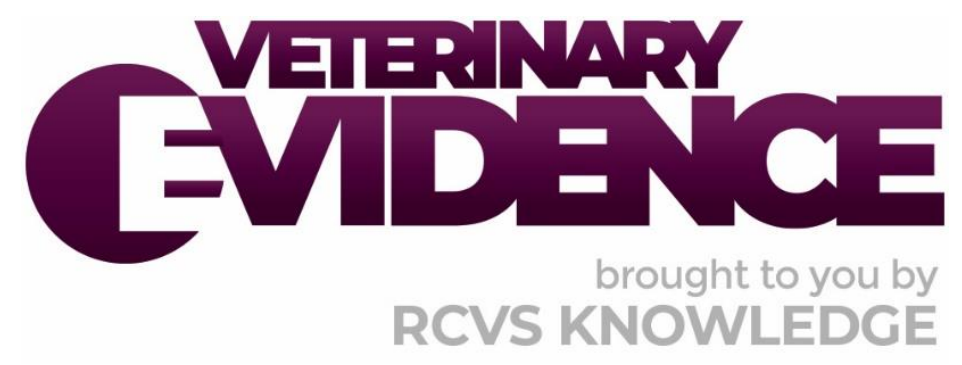

\title{
Does turkey tail as an adjuvant therapy improve the quality of life of canine lymphoma patients?
}

\author{
A Knowledge Summary by
}

Jacqueline Oi Ping Tong BVM\&S Student ${ }^{1^{*}}$

\footnotetext{
${ }^{1}$ Royal (Dick) School of Veterinary Studies, Easter Bush Campus, Midlothian EH25 9RG

* Corresponding Author (jactong48@gmail.com)
}

ISSN: 2396-9776

Published: 10 Sep 2021

in: The Veterinary Evidence journal Vol 6, Issue 3

DOI: https://doi.org/10.18849/ve.v6i3.403

Reviewed by: Simon Bate (BVMS CertSAM MRCVS) and Clare Knottenbelt (BVSC MSc DSAM MRCVS) 


\section{KNOWLEDGE SUMMARY}

\section{PICO question}

In canine lymphoma, does the supplement of turkey tail (Trametes versicolor) as an adjuvant therapy lead to a better quality of life than those that do not?

\section{Clinical bottom line}

\section{Category of research question}

\section{Treatment}

\section{The number and type of study designs reviewed}

One prospective case series was critically appraised

\section{Strength of evidence}

Very weak

\section{Outcomes reported}

The case series assessed appetite and activity level of the canine lymphoma patients. They also measured gastrointestinal toxicity and the incidence of neutropenia

\section{Conclusion}

This prospective case series is insufficient to support the use of turkey tail to enhance the quality of life of canine lymphoma patients. A controlled study is required to evaluate whether the use of turkey tail supplement is useful

\section{How to apply this evidence in practice}

The application of evidence into practice should take into account multiple factors, not limited to: individual clinical expertise, patient's circumstances and owners' values, country, location or clinic where you work, the individual case in front of you, the availability of therapies and resources.

Knowledge Summaries are a resource to help reinforce or inform decision making. They do not override the responsibility or judgement of the practitioner to do what is best for the animal in their care.

\section{Clinical Scenario}

A dog with multicentric lymphoma has been presented to your clinic. In human medicine, evidence has shown that a medicinal mushroom - turkey tail - could modulate the immune response in cancer patients and kill cancer cells in vitro (Habtemariam, 2020). Based on the current evidence in human medicine, your client wishes to know whether the mushroom-derived products, particularly turkey tail, can improve the quality of life of their dog alongside the chemotherapy or palliative care.

\section{The evidence}

One prospective case series (Holliday et al., 2009) was found relevant to the PICO. This case series studied the effect of a mushroom-derived supplement, in conjunction with chemotherapy or palliative treatment, on the quality of life of patients with various types of cancer. Regarding the relevance to the PICO, this Knowledge 
Summary appraised the section of canine lymphoma in this case series only. Due to a lack of control in the case series, the strength of the evidence is weak.

Studies concerning other medicinal mushrooms without turkey tail or other cancer types were not appraised in this Knowledge Summary as they are considered irrelevant here.

\section{Summary of the evidence}

\begin{tabular}{|c|c|}
\hline \multicolumn{2}{|l|}{ Holliday et al. (2009) } \\
\hline Population: & $\begin{array}{l}\text { Dogs with lymphoma staged from IIIA to VB, according to World } \\
\text { Health Organization clinical staging system (Owen \& World Health } \\
\text { Organization, 1980). These dogs received various chemotherapy } \\
\text { protocols based on Veterinary Cooperative Oncology Group (VCOG) } \\
\text { or palliative treatments. Age, sex, breed and weight of these } \\
\text { patients were not specified. Patients with hypercalcaemia were not } \\
\text { excluded. Concurrent supplementation of immune-enhancement } \\
\text { product was not specified as well. }\end{array}$ \\
\hline Sample size: & $\begin{array}{l}\text { Twenty-one dogs with lymphoma diagnosed by cytology. Three of } \\
\text { them were diagnosed with T-cell lymphoma; } 19 \text { of them were } \\
\text { diagnosed with B-cell lymphoma. } \\
\text { One patient staged VB had pulmonary carcinoma concurrently. } \\
\text { Four patients were diagnosed with hypercalcaemia concurrently. }\end{array}$ \\
\hline Intervention details: & $\begin{array}{l}\text { Each dog received immune-enhancement supplements (K9 } \\
\text { Immunity }{ }^{\mathrm{TM}} \text { and K9 Transfer Factor }{ }^{\mathrm{TM}} \text { ), as an adjunct to either } \\
\text { chemotherapy or palliative therapy. } \\
\text { Chemotherapy lasted for } 16-24 \text { weeks, based on one or more of the } \\
\text { following. When the patients relapsed, another protocol was } \\
\text { implemented. For the lymphosarcoma (LSA) patients these included: } \\
\text { - CHOP protocol: cyclophosphamide, doxorubicin } \\
\text { (hydroxydaunorubicin), vincristine (Oncovin }{ }^{\circledR} \text { ) and } \\
\text { prednisone. } \\
\text { - Doxorubicin and dacarbazine } \\
\text { - Vincristine and cyclophosphamide } \\
\text { - Vincristine and lomustine } \\
\text { - Vincristine and chlorambucil } \\
\text { - Single-agent protocol - e.g. chlorambucil or doxorubicin or } \\
\text { lomustine } \\
\text { The protocol of palliative treatment was not mentioned in the } \\
\text { paper. } \\
\text { The number of dogs receiving each treatment protocol was not } \\
\text { stated in the paper. } \\
\text { Immune-enhancement supplement - K9 Immunity } \\
\text { - The active ingredients are polysaccharides derived from six } \\
\text { species of medicinal mushrooms, namely Agaricus } \\
\text { brasiliensis, Cordyceps sinensis, Lentinus edodes, Grifola } \\
\text { frondosa, Ganoderma lucidum, and Trametes versicolor. }\end{array}$ \\
\hline
\end{tabular}




\begin{tabular}{|c|c|}
\hline & $\begin{array}{l}\text { - It was offered as an oral capsule, with each capsule } \\
\text { containing a } 500 \mathrm{mg} \text { mixture of the active ingredients. } \\
\text { - The dose was } 500 \mathrm{mg} \text { per } 4.5 \mathrm{~kg} \text { per day. } \\
\text { Immune-enhancement supplement - K9 Transfer Factor }{ }^{\mathrm{TM}} \text { : } \\
\text { - It contains antibodies (IgA, IgG and IgY), immunoproteins } \\
\text { and proline-rich polysaccharide which aim to enhance the } \\
\text { absorption of } \mathrm{K} 9 \text { Immunity }{ }^{\mathrm{TM}} \text {. } \\
\text { - The immunoproteins were derived from bovine colostrum, } \\
\text { bovine serum and chicken egg yolk. } \\
\text { - Dogs }>11 \mathrm{~kg} \text { received } 3000 \mathrm{mg} \text { of this product (as one } \\
\text { wafer) per day. Dogs } \leq 11 \mathrm{~kg} \text { received } 1 / 2 \text { wafer per day. } \\
\text { The immune-enhancement supplements were administered at } \\
\text { home. }\end{array}$ \\
\hline Study design: & Prospective case series \\
\hline Outcome studied: & 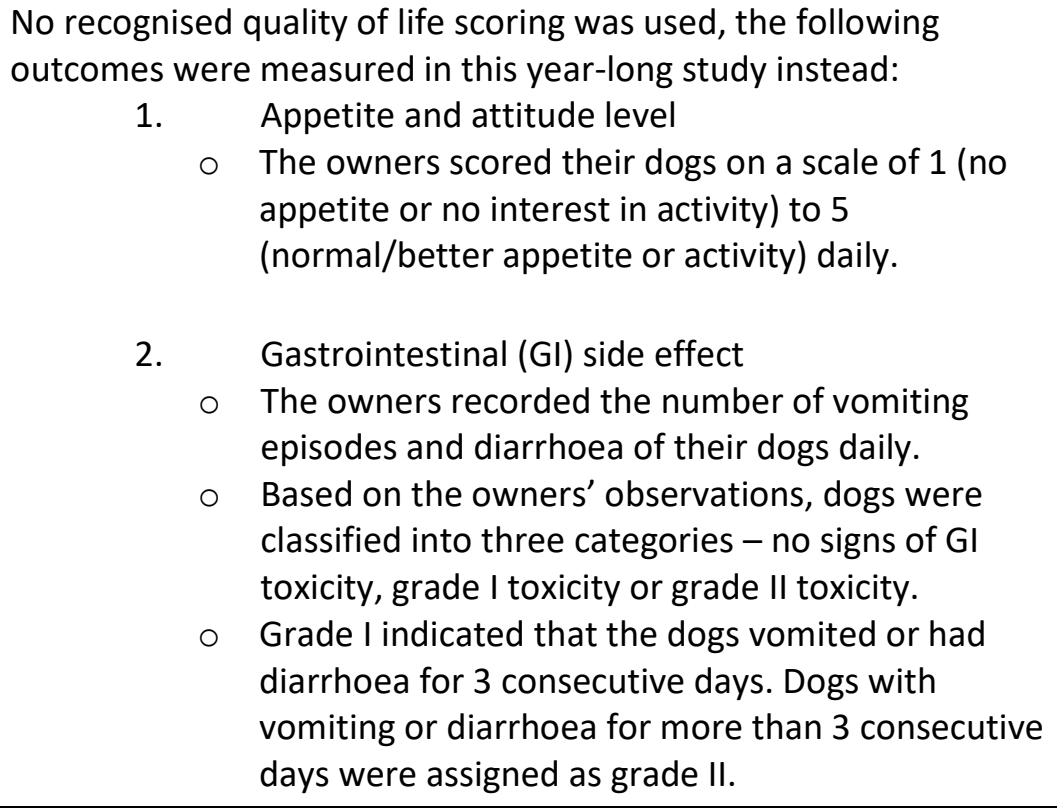 \\
\hline $\begin{array}{l}\text { Main findings: } \\
\text { (relevant to PICO question): }\end{array}$ & 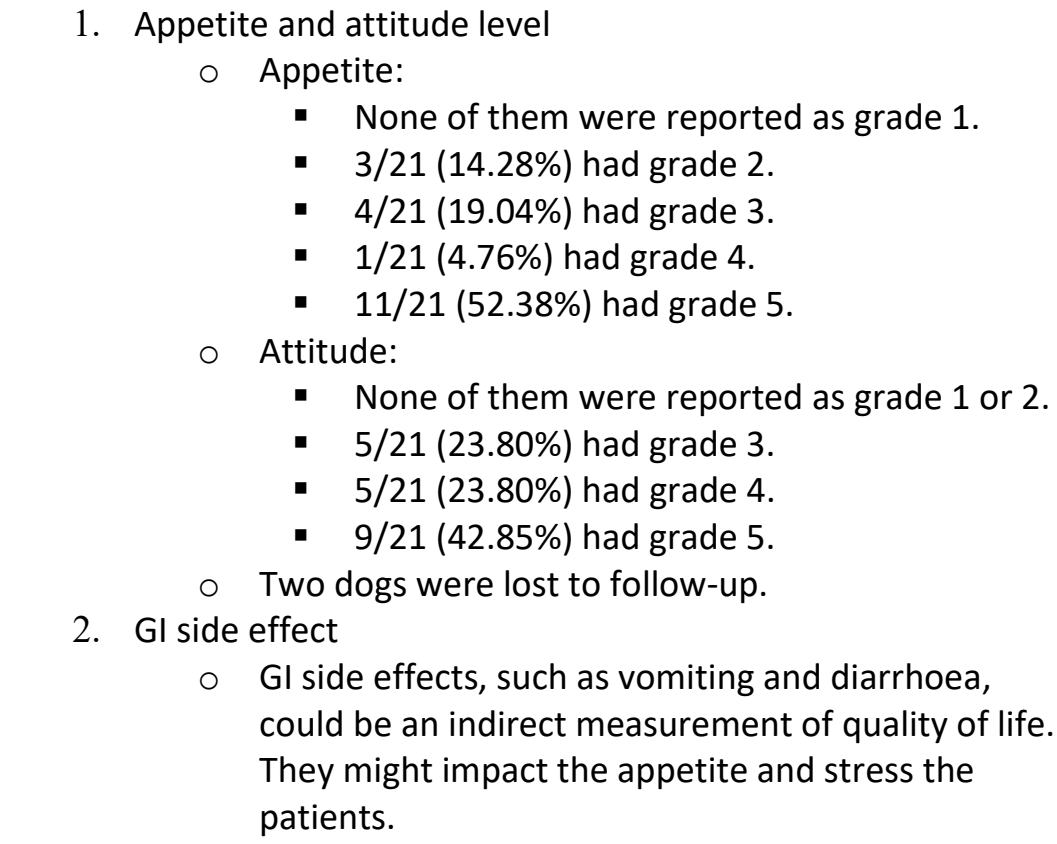 \\
\hline
\end{tabular}




\begin{tabular}{|c|c|}
\hline & $\begin{array}{ll}\circ & 16 / 21(76.19 \%) \text { reported no signs of GI toxicity. } \\
\circ & 5 / 21(23.80 \%) \text { reported with grade I GI toxicity. } \\
\circ & \text { None of them developed grade II. } \\
\circ & \text { VCOG grading system was not used. }\end{array}$ \\
\hline Limitations: & $\begin{array}{l}\text { - No control patients in this study. } \\
\text { - Thall sample size and wide range of different regimes. } \\
\text { - The disease-free interval was not evaluated in this study. } \\
\text { - The data processing on 'appetite and attitude level' was } \\
\text { unclear. } \\
\text { - The description for scoring the 'appetite and attitude' were } \\
\text { subjective and vague. The study failed to use a recognised } \\
\text { quality of life score. } \\
\text { - Study failed to use the standardised VCOG grading system } \\
\text { for chemotherapy side effects. } \\
\text { - A potential conflict of interest was identified. Aloha } \\
\text { Medicinals Inc., the manufacturer of K9 Immunity } \\
\text { employed three authors of this paper and provided funding } \\
\text { to this project. }\end{array}$ \\
\hline
\end{tabular}

\section{Appraisal, application and reflection}

Holliday et al. (2009) published a prospective case series about the effect of a mushroom-derived supplement, $\mathrm{K} 9 \mathrm{Immunity} \mathrm{TM}^{\mathrm{TM}}$, to the health-related quality of life (HRQoL) of canine patients with lymphoma. K9 Immunity ${ }^{\mathrm{TM}}$ contains the derivatives of six species of mushroom, including turkey tail (Trametes Versicolor), and it was offered with $\mathrm{K9}$ Transfer Factor ${ }^{\mathrm{TM}}$ which contains a mixture of immunoproteins. In this year-long case series, the quality of life was measured by appetite and attitude level, and the adverse effect of chemotherapy namely gastrointestinal (GI) toxicity.

In canine cancer patients, the management aim is to achieve and sustain a good HRQoL. Three studies (Iliopoulou et al., 2013; Lynch et al., 2010; and Yazbek \& Fantoni, 2005) have looked into a validated measurement of HRQoL in these patients. They have developed sets of questionnaires for owners to measure the HRQoL of their pets. In these questionnaires owners have been asked to score their pets in terms of their mental status, attitude, appetite, perceived pain level, mobility and hygiene. Owners' perception is useful to assess HRQoL of cancer patients as they are often the very first individuals to recognise behavioural changes when HRQoL starts to be compromised.

Holliday et al. (2009) only made an evaluation on 'activity and appetite level' with owners' perception, and GI toxicity which is the side effect of chemotherapy. In the measurement of 'appetite and attitude level', Holliday et al. (2009) failed to use a clear and validated scoring system. The paper also failed to use the standardised VCOG grading systems to assess GI toxicity. It therefore makes comparisons to other or future studies difficult. Other aspects of HRQoL, such as perceived pain level and mental status, have not been addressed by them either. Therefore, their case series did not fully and effectively assess HRQoL of the canine lymphoma patients.

GI toxicity includes vomiting and diarrhoea which may impact patients' HRQoL, as they create distress, pain and inappetence. However, Mellanby et al. (2003) reported that some owners perceived an improved HRQoL in their dogs despite the complication associated with chemotherapy. The measurement of Gl toxicity may not truly reflect the HRQoL.

All dogs in the study received a mushroom-derived product and another product in conjunction with either chemotherapy or palliative treatment. There was no control group and therefore it impossible to establish the impact of mushroom-derived supplement on the adverse effects of chemotherapy and HRQoL 
Unfortunately, the demographic data, such as age, sex and breed, was not specified. Together with the small sample size $(n=21)$, it is questionable whether this case series represents the wider canine lymphoma population.

A potential conflict of interest is identified in this study. Three of the authors of this paper were employed by Aloha Medicinals Inc., which is the pharmaceutical company manufacturing the immune-enhancement supplement used. In addition, the study was funded by this company. Given a lack of control in this study, there is a risk of bias in data presentation which the readers should be cautious about.

The Holliday et al. (2009) case series should be considered a preliminary study that may show the potential of mushroom-derived supplements in improving the HRQoL of canine lymphoma patients. However, the overall strength of evidence is very weak due to the absence of a control population, incomplete assessment of patients HRQoL, failure to use the VCOG grading system for all side effects, questionable representativeness to the canine lymphoma population, and the limitations in the study design. This prospective case series is insufficient to support the use of turkey tail-derived products to enhance the health-related quality of life of canine lymphoma patients receiving conventional therapies.

\section{Methodology Section}

\begin{tabular}{|c|c|}
\hline \multicolumn{2}{|l|}{ Search Strategy } \\
\hline $\begin{array}{r}\text { Databases searched and dates } \\
\text { covered: }\end{array}$ & $\begin{array}{l}\text { CAB Abstracts } 1973-2021 \text { Week } 14 \\
\text { PubMed NCBI } 1960-2021 \mathrm{Apr}\end{array}$ \\
\hline Search terms: & $\begin{array}{l}\text { CAB Abstracts: } \\
\text { 1. dog or dogs or canine* or bitch* or exp dogs/ or exp } \\
\text { bitches/ or exp canis/ } \\
\text { 2. cancer* or tumour* or tumor* or malignan* or neoplas* or } \\
\text { lymphoma* or lymphosarcoma* or exp cancer/ or exp } \\
\text { neoplasms/ } \\
\text { 3. (mushroom* or fungus or fungi or 'turkey tail' or yunzhi or } \\
\quad \text { yun-zhi or 'yun zhi' or ((Trametes or Coriolus or Polyporus) } \\
\text { and versicolor)) } \\
\text { 4. } 1 \text { and } 2 \text { and } 3 \\
\text { PubMed: } \\
\text { (dog[Title/Abstract] OR dogs[Title/Abstract] OR } \\
\text { canine[Title/Abstract] OR bitch[Title/Abstract]) AND } \\
\text { (cancer[Title/Abstract] OR tumour[Title/Abstract] OR } \\
\text { tumor[Title/Abstract] OR neoplasm[Title/Abstract] OR } \\
\text { lymphoma[Title/Abstract] OR lymphosarcoma[Title/Abstract]) AND } \\
\text { (mushroom OR fungus OR fungi OR 'turkey tail' OR yunzhi OR yun-zhi } \\
\text { OR 'yun zhi' OR ((Trametes OR Coriolus OR Polyporus) AND } \\
\text { versicolor)) AND veterinary [sb] }\end{array}$ \\
\hline Dates searches performed: & 12 Apr 2021 \\
\hline
\end{tabular}




\section{Exclusion / Inclusion Criteria}

Exclusion: - Irrelevant to the PICO:

- Species other than canine

- Turkey tail was not included in the adjuvant supplement

- Studies which did not involve lymphoma

- Reviews, book chapters or conference proceedings

- Articles not written in English

Inclusion: Any published paper relevant to the PICO and available in English.

\begin{tabular}{|c|c|c|c|c|c|c|}
\hline \multicolumn{7}{|c|}{ Search Outcome } \\
\hline Database & $\begin{array}{c}\text { Number } \\
\text { of } \\
\text { results }\end{array}$ & $\begin{array}{l}\text { Excluded - } \\
\text { Irrelevant }\end{array}$ & $\begin{array}{c}\text { Excluded - } \\
\text { Book } \\
\text { chapters/reviews/conferen } \\
\text { ce proceedings }\end{array}$ & $\begin{array}{l}\text { Excluded - } \\
\text { Non- } \\
\text { English } \\
\text { articles }\end{array}$ & $\begin{array}{l}\text { Excluded - } \\
\text { Duplicates }\end{array}$ & $\begin{array}{c}\text { Total } \\
\text { relevant } \\
\text { papers }\end{array}$ \\
\hline $\begin{array}{l}\text { CAB } \\
\text { Abstracts }\end{array}$ & 299 & 296 & 2 & 0 & 0 & 1 \\
\hline PubMed & 420 & 420 & 0 & 0 & 0 & 0 \\
\hline Total relev & apers & duplica & moved & & & 1 \\
\hline
\end{tabular}

\section{CONFLICT OF INTEREST}

The author declares no conflict of interest.

\section{REFERENCES}

1. Habtemariam, S. (2020). Trametes versicolor (Synn. Coriolus versicolor) Polysaccharides in Cancer Therapy: Targets and Efficacy. Biomedicines. 8(5), 135.

DOI: https://doi.org/10.3390/biomedicines8050135

2. Holliday, J. C., Gianotti, B. M., Cleaver, M. P., Mullins, M. N. \& West, S. Y. (2009). Preclinical evaluation of concurrent medicinal mushroom-based immune-enhancement supplementation in dogs undergoing chemotherapy for various cancers. International Journal of Medicinal Mushrooms. 11(2), 167-184. DOI: http://dx.doi.org/10.1615/IntJMedMushr.v11.i2.60

3. Iliopoulou, M. A., Kitchell, B. E. \& Yuzbasiyan-Gurkan, V. (2013). Development of a survey instrument to assess health-related quality of life in small animal cancer patients treated with chemotherapy. Journal of the American Veterinary Medical Association. 242(12), 1679-1687. DOI: https://doi.org/10.2460/javma.242.12.1679

4. Lynch, S., Savary-Bataille, K., Leeuw, B. \& Argyle, D. J. (2010. Development of a questionnaire assessing health-related quality-of-life in dogs and cats with cancer. Veterinary and Comparative Oncology. 9(3), 172-182. DOI: https://doi.org/10.1111/j.1476-5829.2010.00244.x 
5. Mellanby, R. J., Herrtage, M. E. \& Dobson, J. M. (2006). Owners' assessments of their dog's quality of life during palliative chemotherapy for lymphoma. Journal of Small Animal Practice. 44(3), 100-103. DOI: https://doi.org/10.1111/j.1748-5827.2003.tb00127.x

6. Owen, L. N. \& World Health Organization. (1980). TNM Classification of Tumours in Domestic Animals/edited by L.N. Owen. (No. VPH/CMO/80.20). World Health Organization.

7. Veterinary Cooprative Oncology Group. (2016). Veterinary cooperative oncology group - common terminology criteria for adverse events (VCOG-CTCAE) following chemotherapy or biological antineoplastic therapy in dogs and cats v1.1. Veterinary and Comparative Oncology. 14(4), 417-446. DOI: https://doi.org/10.1111/vco.283

8. Yazbek, K. V. \& Fantoni, D. T. (2005). Validity of a health-related quality-of-life scale for dogs with signs of pain secondary to cancer. Journal of the American Veterinary Medical Association. 226(8), 13541358. DOI: https://doi.org/10.2460/iavma.2005.226.1354 


\section{EVIIDEFeE

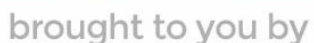 \\ RCVS KNOWLEDGE}

\section{Intellectual Property Rights}

Authors of Knowledge Summaries submitted to RCVS Knowledge for publication will retain copyright in their work, and will be required to grant RCVS Knowledge a non-exclusive license of the rights of copyright in the materials including but not limited to the right to publish, re-

publish, transmit, sell, distribute and otherwise use the materials in all languages and all media throughout the world, and to license or permit others to do so.

\section{Disclaimer}

Knowledge Summaries are a peer-reviewed article type which aims to answer a clinical question based on the best available current evidence. It does not override the responsibility

of the practitioner. Informed decisions should be made by considering such factors as individual clinical expertise and judgement along with patient's circumstances and owners' values. Knowledge Summaries are a resource to help inform and any opinions expressed within the Knowledge Summaries are the author's own and do not necessarily reflect the view of the RCVS Knowledge. Authors are responsible for the accuracy of the content. While the

Editor and Publisher believe that all content herein are in accord with current recommendations and practice at the time of publication, they accept no legal responsibility

for any errors or omissions, and make no warranty, express or implied, with respect to material contained within.

For further information please refer to our Terms of Use.

RCVS Knowledge is the independent charity associated with the Royal College of Veterinary Surgeons (RCVS). Our ambition is to become a global intermediary for evidence based veterinary knowledge by providing access to information

that is of immediate value to practicing veterinary professionals and directly contributes to evidence based clinical decision-making.

\section{https://www.veterinaryevidence.org/}

RCVS Knowledge is a registered Charity No. 230886.

Registered as a Company limited by guarantee in England and Wales No. 598443.

Registered Office: Belgravia House, 62-64 Horseferry Road, London SW1P 2AF

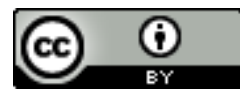

This work is licensed under a Creative Commons Attribution 4.0 International License 